\title{
Evaluation of possibilities of application of web-based tool for effective identification of mechanical properties of materials
}

\author{
Ocena możliwości zastosowania internetowego narzędzia \\ do efektywnej identyfikacji własności mechanicznych materiałów
}

ŁUKASZ WOLSKI
MAGDALENA KOPERNIK*

The main purpose of the work is to present and test the developed web-based tool to identify parameters of rheological equations, whose functionality according to the presented results is comparable to existing desktop applications. The developed web-based application with a user-friendly interface uses selected optimization methods (Powell and Hooke-Jeeves algorithms). Criteria for selecting optimization methods are: robustness and frequent application to identification problems described in literature. Testing the developed application consists of comparing the identified stress-strain curves obtained from mechanical tests using the developed tool and commercial desktop application, and performing efficiency tests for the analyzed examples of rheological equations and optimization methods. For this purpose, two material models were used: a simple Hollomon's model and a multi-parameter model used for steel, in which the influence of softening during the dynamic recrystallization is insignificant. The presented software is implemented in technologies such as JDK 1.8, Spring Framework and PrimeFaces, and passes the efficiency tests successfully.

KEYWORDS: mechanical tests, mechanical properties, optimization methods, rheological model, inverse analysis, web application

Głównym celem pracy jest przedstawienie i przetestowanie opracowanego narzędzia webowego do identyfikacji parametrów równań reologicznych, którego funkcjonalność - zgodnie z uzyskanymi wynikami - jest porównywalna z istniejącymi aplikacjami desktopowymi. Opracowana aplikacja internetowa, z przyjaznym dla użytkownika interfejsem, wykorzystuje wybrane metody optymalizacji (algorytmy Powella oraz Hooke'a-Jeevesa). Kryteria wyboru metod optymalizacyjnych to odporność rozwiazania na zaburzenia i czeste zastosowanie do problemów odwrotnych opisanych w literaturze. Przetestowanie opracowanej aplikacji polega na porównaniu zidentyfikowanych krzywych naprężenie-odkształcenie, uzyskanych z testów mechanicznych z wykorzystaniem opracowanego narzędzia i komercyjnej aplikacji desktopowej, oraz na przeprowadzeniu testów wydajnościowych dla analizowanych przykładów równań reologicznych i metod optymalizacyjnych. W tym celu posłużono się dwoma modelami materiałowymi: prostym modelem Hollomona i modelem wieloparametrowym, stosowanym dla stali, w którym wpływ zmiękczania podczas rekrystalizacji dynamicznej jest nieznaczny. Prezentowane oprogramowanie jest wdrażane w takich technologiach, jak JDK 1.8, Spring Framework czy PrimeFaces, i pomyślnie przechodzi testy wydajności.

SŁOWA KLUCZOWE: testy mechaniczne, własności mechaniczne, metody optymalizacji, model reologiczny, analiza odwrotna, aplikacja webowa

\footnotetext{
* Mgr inż. Łukasz Wolski (Iwolski0@gmail.com) - Comarch SA, dr hab. Magdalena Kopernik (kopernik@agh.edu.pl)-AGH Akademia Górniczo-Hutnicza im. S. Staszica w Krakowie
}

DOI: https://doi.org/10.17814/mechanik.2018.7.89

The developed web-based application is available at: https://github.com/johnnieskywalker/rheology-web

The most popular and applied in industry mechanical properties of materials are determined in mechanical tests, such as tension and compression tests, as well as in more sophisticated experiments using digital image correlation or extensometers [1]. The most important material properties determined during mechanical tests are yield stress and ultimate stress that describe material's strength for engineering design $[2,3]$. Other parameters that influence flow stress curves like friction coefficient, state of stress and preheating are identified by means of inverse analysis [4]. The obtained mechanical properties are presented in the form of constitutive equations, which can have very complicated mathematical formulation for example to describe phenomena such as effect of softening due to dynamic recrystallization [4]. Constitutive equations might be categorized into four groups: elastic, viscoelastic, plastic and viscoplastic. The most popular and often used rheological equations that describe stress-strain curves are: Hollomon, Zener-Hollomon, Levy-Mises, Hockett-Sherby, Swift and Avrami equations [3,5-8].

The known approach to identification of parameters of constitutive equations has many disadvantages, for example large data files and therefore, necessity of timeconsuming data mining. The needed steps of identification can be done in a commercial dedicated software added to materials testing machines and desktop applications (for example Excel, Origin, Statistica, etc.) [6].

The identification of constitutive equations of materials applied in industry is usually done using an inverse method with defined goal function and optimization algorithms. The mathematical form of goal function is defined as a sum of RMSE (root mean squared errors) between measured and calculated values and each sum is divided by amount of measurements of a certain value [5]. If for example a load and a radius are measured during a mechanical test, the goal function needs to contain a sum of root mean squared errors between the load and the radius measured and calculated, and divided by a sum of measurements [5]. Optimization methods may be grouped into gradient methods and derivative-free, direct methods. Identification problems of rheological parameters in industry are often solved with direct methods because it is rarely possible to calculate gradient of complicated goal function during program runtime. Criterion used for comparison of optimization methods is a convergence towards solution which is affected by factors like: problem dimensionality, non-smoothness, missing bounds on variables, noise in objective function, etc. $[7,8]$. Examples of software that uses derivative-free optimization methods are commercial programs: TOMLAB/MULTIMIN, TOMLAB/GLCCLUSTER and non-commercial SNOBFIT and MCS [8]. 
The purpose of the work is to implement and test the developed web-based tool to identify parameters of rheological equations, whose functionality is comparable to existing desktop applications. The developed web-based application with a user-friendly interface, uses selected optimization methods (Powell and Hooke-Jeeves algorithms) and inverse analysis using the objective function. Reasons for selecting the Powell algorithm are quickness, reliability and accuracy in solving problems with differentiable goal functions. Criteria for selecting the $\mathrm{HJ}$ algorithm are relatively good quickness, reliability and accuracy in solving problems with both differentiable and non-differentiable objective functions [9]. Testing the developed application consists of comparing the identified stress-strain curves obtained from mechanical tests using the developed tool and commercial desktop application, and performing efficiency tests for the analyzed examples of rheological equations and optimization methods. For this purpose, two material models were used: a simple Hollomon's model and a multi-parameter model used for steel, in which the influence of softening during the dynamic recrystallization is insignificant. The presented software is implemented in technologies such as JDK 1.8, Spring Framework and PrimeFaces.

Summarizing, the purpose of the work was to present a universal, easy to use and useful browser tool available to everyone, including metallurgists, engineers who use the MS Excel Solver.

\section{Materials and methods}

This chapter is a brief overview of technologies and algorithms used in the developed web application. The last part of this chapter is dedicated to explanation of experiments and material models being input data for the presented application.

- Applied Java libraries and web technologies. Backend of the proposed web application is developed in the newest, eight version of Java programming language. Additional libraries sources are imported with Apache Maven - project management tool that realizes project object model. Once used library or framework is defined as dependency, Apache Maven downloads all necessary files from remote repositories. Spring Framework comprehensive solution that allows to build enterprise-ready applications without necessity of downloading large resource of framework's code but only selected modules. Some of Spring's features used in the developed application are: dependency injection, http integration and object relational mapping (ORM) integration. Hibernate is chosen as ORM and data persistence framework. User interface is built using JSF (Java Server Faces) components provided by PrimeFaces framework. Frontend of the PrimeFaces application is implemented in XHTML (Extensible Hypertext Markup Language) that is rendered to native HTML (Hypertext Markup Language) which is send to browser once page is requested. XHTML contains tags that allow pointing requested backend resources and actions implemented in JSF Managed Beans. One of the biggest PrimeFaces features are partial page rendering (PPR) and view-processing based on JSF2 API (Java Server Faces 2 Application Programming Interface) that by using AJAX (Asynchronous JavaScript And XML) allows to select elements of website that are reloaded in client's browser [9]. Both PrimeFaces and additional presented application scripts are based on jQuery, one of most pop- ular JavaScript library [10]. Presented application is deployed to Apache Tomcat 8.0 Server which serves as both Java servlet container and web server [11].

The libraries used in this work are widely used in business and industrial applications, but according to the literature review, no one has created an easy-to-use web tool for identifying parameters of rheological equations. Our application can facilitate the work of people performing strength tests, which can benefit from it by connecting through a web browser, which is a novelty, because so far they had to install specialized software on their computers.

- Approximation and optimization algorithms. Mechanical tests usually do not provide all parameters of a rheological equation. Comparisons of an experimental stress-strain curve with a constitutive equation or with the curve used for the finite element simulation allow evaluating parameters of the rheological equation $[3,4,6]$. The stress-strain curve calculated from the rheological equation is iteratively modified to minimize its discrepancy from an experimental data [3]. Such approach is called an inverse method. Discrepancy between experimental and computed stress-strain curves is achieved by finding a minimum of goal function $[4,6-8]$. The proposed goal function for compression tests is a sum of root mean squared errors between an experimental and a calculated stress:

$$
\Phi=\sqrt{\frac{1}{N} \sum_{i=1}^{n}\left(\sigma_{\mathrm{m} i}-\sigma_{\mathrm{c} i}\right)^{2}}
$$

where: $\sigma_{\mathrm{m} i}, \sigma_{\mathrm{c} i}-$ the measured and calculated stress respectively.

For searching the minimum of goal function two popular derivative-free optimization algorithms were selected: Hooke-Jeeves and Powell methods [8, 12]. Convergence of both used methods was proved in literature $[8,12]$. Advantages of Hooke-Jeeves method are: simplicity, flexibility and reliability. The problem of the uniqueness of the solution in this work does not occur, because the applied Hooke-Jeeves and Powell algorithms are resistant to it [13]. The optimization methods applied in the present paper are not revolutionary but fine, precise and fast enough for usage in the web application [14].

Powell-based methods are widely used in many numerical solvers. Hooke-Jeeves algorithm is based on sequential examination of a trial solution generated by a certain strategy. Initial parameters of Hook-Jeeves algorithm are: a step size and a search point, which are later changed during algorithm iterations. The step size $s$ ranges from 0.05 to 1. Hook-Jeeves method uses two kinds of steps: an exploration and a pattern search steps. Searches are performed at an iteration index $i$ ranging from 1 to $n$. At a search point $y$ where $x=y$ a function is evaluated at $\left(x+s e_{i}\right)$, where $e_{i}$ is an unit vector along a coordinate direction $x$. If the function value at $\left(x+s e_{i}\right)$ is lower than a value at $x$, the search point is being updated to be $x=\left(x+s e_{i}\right)$. Otherwise the function is evaluated at $\left(x-s e_{i}\right)$. If both evaluations are unsuccessful the original $x$ is retained. When $y$ is an initial point and $x$ is a new point, an exploration is successful if the goal function value at $x$ is lower than value at $y$ by a predetermined amount. Powell method involve constructing conjugate directions without usage of derivatives. As searching along conjugate directions is finished, a larger step from a current point along coordinate directions is introduced in order to ensure convergence. The proposed application uses 
Powell algorithm implementation provided by JCobyla as Java library. Results achieved by the presented application are compared with the commercial Excel Solver that uses a generalized reduced gradient (GRG2) algorithm for a nonlinear optimization problems.

- Mechanical tests and constitutive material models. The presented application input data sources may be results of various compression tests: uniaxial compression (UC), ring compression (RC) and plane strain compression (PSC) [5]. Such tests are performed using hardware like Gleeble 3800 simulator and INSTRON servo hydraulic machine. The application was tested with an input data from simulations of compression tests performed in JMatPro. Presented identification task data is a stress-strain curve of a micro alloyed steel $38 \mathrm{MnSV} 4$ in $800^{\circ} \mathrm{C}$ and with a strain rate equal $1 \mathrm{~s}^{-1}$.

First task: first constitutive model is a simple Hollomon's equation $[15,16]$ :

$$
\sigma_{i}^{\mathrm{c}}=k \varepsilon_{i}^{n}
$$

where: $\sigma_{i}^{\mathrm{c}}$ is a calculated stress, $\varepsilon_{i}$ is a corresponding strain and optimized parameters are $k-a$ material constant and $n-$ a strain hardening index.

Second task: second investigated rheological equation describes material with a minor effect of recrystallization softening [4]:

$\sigma_{\mathrm{p}}=\sqrt{3}\left[W K_{0} \varepsilon^{n} \exp \left(\frac{\beta}{T}\right)+(1-W) K_{\mathrm{S}} \exp \left(\frac{\beta_{\mathrm{S}}}{T}\right)\right](\sqrt{3} \dot{\varepsilon})^{m}$

where: $\quad W=\exp \left(-R_{0} \varepsilon\right), K_{0}, n, \beta, K_{\mathrm{s}}, \beta_{\mathrm{s}}, m, R_{0}$ are parameters identified with an inverse analysis.

Reason for selecting Eqs (2) and (3) was a comparison of inverse analysis results obtained using the popular Eq. (2), and more specialized the Eq. (3).

The Hollomon's equation is very simple, while the second equation used in this work has 8 parameters. The tool developed in the present work allows to approximate any data using any curves and there is no limit on the number of parameters.

\section{Results}

- Scheme of web application. A user interface of the presented web application is based on a template defined in a XHTML file. The GUI template contains three elements shown in Fig. 1. A navigation bar (part 1 of Fig. 1) allows to control a calculation engine by selecting an algorithm, a material model etc. and typical actions like logging user out of the system. A page content (part 2 of Fig. 1) is a place reserved for certain screens displayed in the web application: a data loading view, a table view, a chart view, a terminal view. Each of the application views is a separate $\mathrm{XHTML}$ file which hypertext content is inserted into a part of template. A dock menu in the bottom of the GUI template shown in part 3 of the Fig. 1 allows switching between the application screens that are displayed in the content part.

A data loading view allows to load files with stress-strain curves data to the system. After a file is loaded a stress-strain data is presented in the table, chart and terminal views. Calculations may be set up and run using both the navigation bar and terminal. When calculations are finished the results are updated to all web application screens that allow comparing the calculated stress-strain curves with the experimental data. Below both the table and chart view additional table with the goal function and the equation parameters values before and after calculations are displayed.

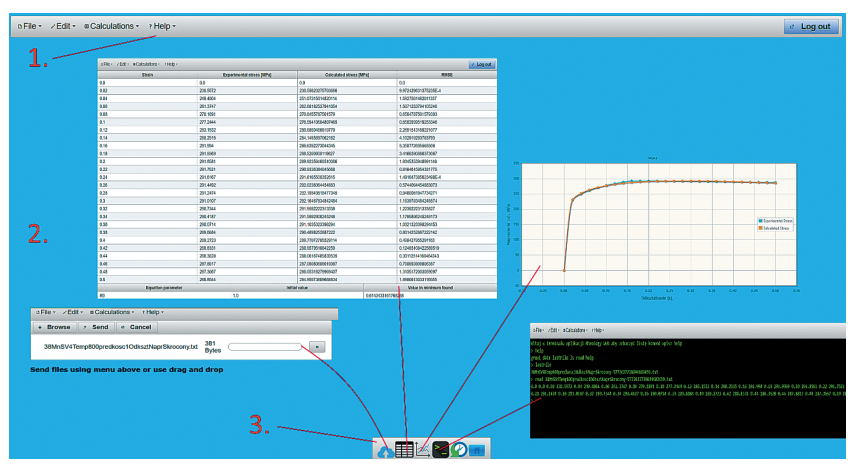

Fig. 1. A main template of the web application GUI: 1 - a navigation bar, $2-$ a view content and 3 - a dock menu

The application GUI sends requests which are handled by JSF Bean classes. For each of the application's screens „ManagedBean” class handling screen's specific logic is defined. Actions and data that are common to all of application's screens are provided by „ViewsDataController" class. Example of class dependencies realizing application's data flow is shown on an UML class diagram in Fig. 2. A handling file uploading event, a reading file is processed by „FileUploadView”. Once data from an uploaded file is processed successfully it is sent to „ViewsDataController" class which provides a loaded data to all screens available in the presented application.

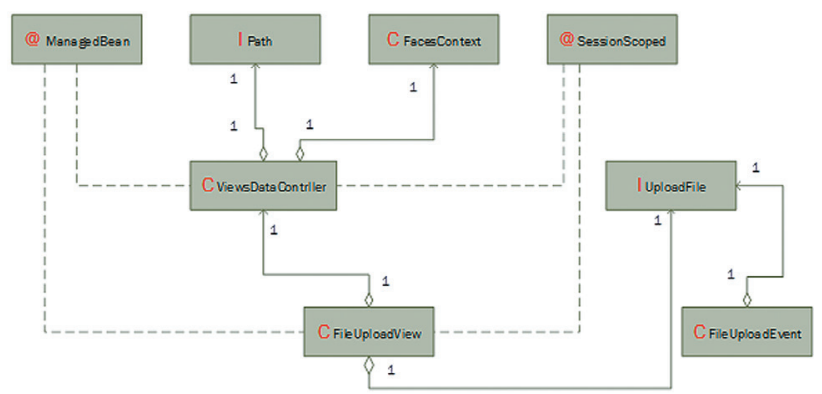

Fig. 2. An UML class diagram presents dependencies between classes processing an uploaded file

The functionalities available in the developed application are basic (they can be expanded because it is possible due to the application architecture), but they enable to get a solution without pre-processing of data or manually manipulation while drawing graphics (no need to scale, etc.), everything happens automatically and quickly.

- Tasks of material model identification. Two tasks are solved with the developed software. Both of the tasks use a stress-strain curve of a micro alloyed steel $38 \mathrm{MnSV} 4$. In the first task a well-known Hollomon's material model given by the Eq. (2) was used. In contrary to the task 1, a more specialized model described by the Eq. (3) was used in the second task. Results of both tasks show possibilities of the developed application that allows to use various models for solving inverse problems. The approximated stress-strain curves obtained with implemented optimization methods in the presented application are compared with results obtained with the commercial MS Excel Solver. Results of the task 1 obtained with the developed software using $\mathrm{HJ}$ algorithm and Excel Solver are shown in Table I. Starting points of the parameters of 
the Hollomon's material model were the same for both the commercial and developed tool.

The experimental stress-strain curve for $38 \mathrm{MnSV} 4$ steel is compared with curves obtained using the proposed web application and the Excel Solver in Fig. 3.

The goal function Eq. (1) combined with rheological Eq. (2) minimum values identified using the developed and commercial software are shown in Table II. The goal function minima found by both compared solutions are nearly the same. Minimum approximated by the Excel Solver is slightly smaller than by the developed software.

The last comparison of solutions, shown in Table III is a percent of stress-strain curve points approximated with the RMSE less than 5.

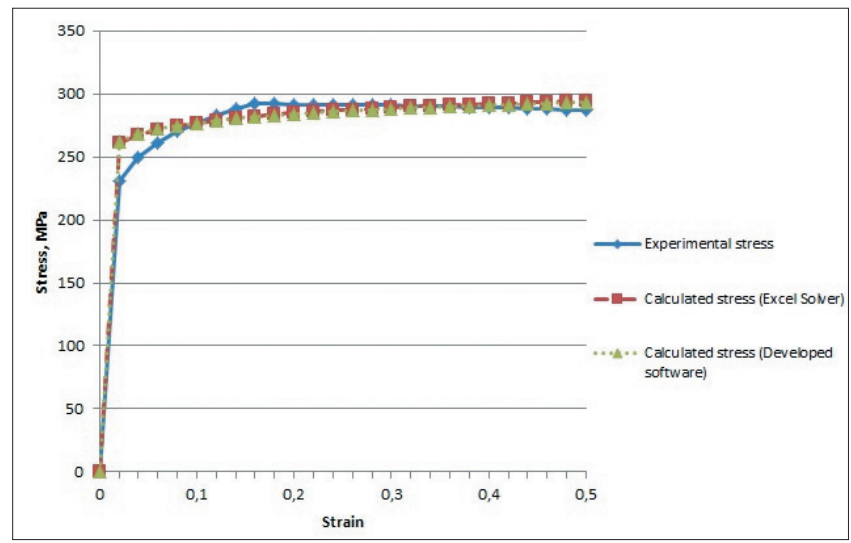

Fig. 3. Task 1: the stress-strain curves approximated using the developed software and commercial Excel Solver

TABLE I. Task 1: Starting points of the parameters of the Hollomon's equation, values of parameters identified by the developed software and MS Excel Solver

\begin{tabular}{|c|c|c|c|}
\hline $\begin{array}{c}\text { Symbol of } \\
\text { parameter }\end{array}$ & $\begin{array}{c}\text { Starting } \\
\text { points }\end{array}$ & $\begin{array}{c}\text { Values identified } \\
\text { using developed } \\
\text { software }\end{array}$ & $\begin{array}{c}\text { Values identified } \\
\text { using Excel Solver }\end{array}$ \\
\hline$k, \mathrm{MPa}$ & 0.1 & 300.76 & 302.87 \\
\hline $\mathrm{n}$ & 0.1 & 0.035 & 0.038 \\
\hline
\end{tabular}

TABLE II. Task 1: the goal function Eq. (1) minimum value identified using the Excel Solver and developed software

\begin{tabular}{|c|c|}
\hline $\begin{array}{c}\text { Minimum function Eq. (1) value } \\
\text { identified using solver }\end{array}$ & $\begin{array}{c}\text { Minimum function Eq. (1) value } \\
\text { identified using developed software }\end{array}$ \\
\hline 157.24 & 157.40 \\
\hline
\end{tabular}

TABLE III. Task 1: Percent of approximated points with the RMSE (root mean squared error) lower than 5

\begin{tabular}{|c|c|}
\hline Software & $\begin{array}{c}\text { Percent of stress-strain points } \\
\text { approximated with RMSE }<5\end{array}$ \\
\hline $\begin{array}{c}\text { Developed software using } \\
\text { HJ algorithm }\end{array}$ & $57 \%$ \\
\hline $\begin{array}{c}\text { Excel Solver } \\
\text { (using GRG2 algorithm) }\end{array}$ & $53 \%$ \\
\hline
\end{tabular}

The task 2 uses the same input data as the task 1 described in the previous section. In contrary to the task 1 , the rheological Eq. (3) was used in the task 2 to approximate the stress-strain curves. Hooke-Jeeves was an optimization method used in the developed software's solution. Starting points of the parameters and result values of the Eq. (3) are presented in Table IV. The stress-strain curves obtained as a result of the task 2 are compared with the experimental curve in Fig. 4.

The goal function Eq. (1) combined with the rheological Eq. (3) minimum values identified using the developed and commercial software are shown in Table V. Minimum of the goal function found by the developed application is nearly three times greater than found by the Excel Solver.
The Table VI compares solutions of the task 2 obtained using the developed and commercial software by presenting a percent of total stress-strain curve points, that are approximated with the RMSE lower than 5.

TABLE IV. Task 2: Starting points of the parameters of the equation (3), values of the parameters identified by the developed software and Excel Solver

\begin{tabular}{|c|c|c|c|}
\hline $\begin{array}{c}\text { Symbol of } \\
\text { parameter }\end{array}$ & $\begin{array}{c}\text { Starting } \\
\text { points }\end{array}$ & $\begin{array}{c}\text { Values identified using } \\
\text { developed software }\end{array}$ & $\begin{array}{c}\text { Values identified } \\
\text { using Excel Solver }\end{array}$ \\
\hline$R_{0}$ & 1.0 & 1.129 & 2.410 \\
\hline$K_{0}$ & 4.0 & 7.488 & 9.211 \\
\hline$n$ & 1.0 & 0.096 & 0.127 \\
\hline$B$ & 1.0 & 3.096 & 14.474 \\
\hline$K_{\mathrm{s}}$ & 1.0 & 5.184 & 6.526 \\
\hline$\beta_{\mathrm{s}}$ & 1.0 & 3.622 & 0.010 \\
\hline$m$ & 6.0 & 5.980 & 5.721 \\
\hline
\end{tabular}

TABLE V. Task 2: the goal function Eq. (1) minimum value identified using the Excel Solver and developed software

\begin{tabular}{|c|c|}
\hline $\begin{array}{c}\text { Minimum function Eq.(1) value } \\
\text { identified using solver }\end{array}$ & $\begin{array}{c}\text { Minimum function Eq. (1) value identified } \\
\text { using developed software }\end{array}$ \\
\hline 28.741 & 74.942 \\
\hline
\end{tabular}

TABLE VI. Task 2: a percent of approximated points with the RMSE (root mean squared error) lower than 5

\begin{tabular}{|c|c|}
\hline Software & $\begin{array}{c}\text { Percent of stress-strain points } \\
\text { approximated with RMSE }<5\end{array}$ \\
\hline $\begin{array}{c}\text { Developed software using } \\
\text { HJ algorithm }\end{array}$ & $81 \%$ \\
\hline $\begin{array}{c}\text { Excel Solver } \\
\text { (using GRG2 algorithm) }\end{array}$ & $96 \%$ \\
\hline
\end{tabular}

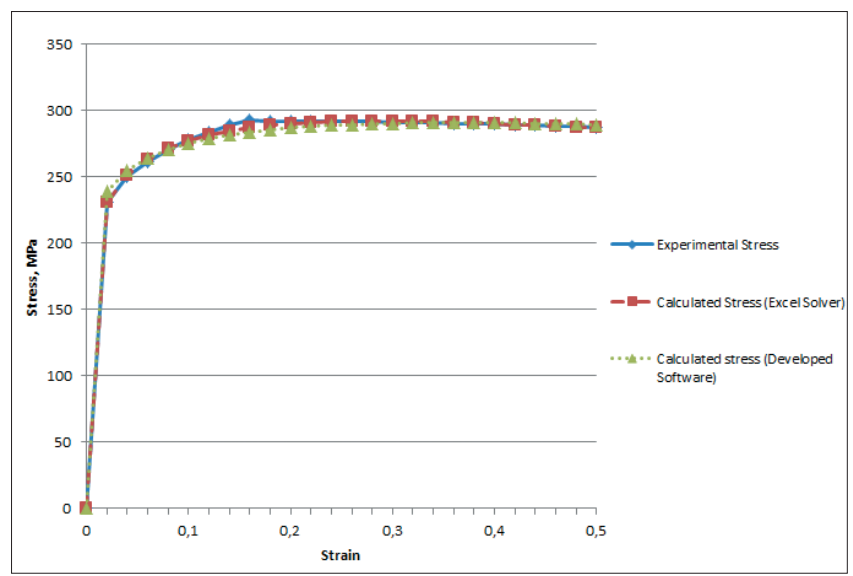

Fig 4. Task 2: the stress-strain curves approximated using the developed software and commercial Excel Solver

- Web application efficiency. Due to the characteristics of the web application, time is very important feature of proper work of the implemented computational algorithms. The web-developer cannot bring the situation, in which the user waits for the response of the server containing results for more than a few seconds after the calculation runs. Counting time measures were done according to the number of points of the stress-strain curves and material model, as well as the number of parameters to change the complexity of the objective function. The developed application's server was hosted on a laptop Lenovo y510p with a $2.40 \mathrm{GHz}$ Intel ${ }^{\circledR}$ Core $^{\mathrm{TM}}$ i7-4700MQ CPU. The application was tested only in a local network. No load tests for the application were performed by multiple users at once. Table VII compares time of calculations of single task depending on the implemented algorithm, material model and a size of input data. 
TABLE VII. Time of single equation identification depending on an input data

\begin{tabular}{|c|c|c|c|c|}
\hline Search method & Rheological equation & $\begin{array}{c}\text { Number of parameters } \\
\text { of equation }\end{array}$ & $\begin{array}{c}\text { Number of stress-strain } \\
\text { curve points }\end{array}$ & Time of calculation, ms \\
\hline Hooke-Jeeves & $(2)$ & 2 & 2 & 2 \\
\hline Hooke-Jeeves & $(3)$ & 7 & 2 & 2 \\
\hline Hooke-Jeeves & $(2)$ & 2 & 2 & 82 \\
\hline Hooke-Jeeves & $(3)$ & 7 & 61 & 90 \\
\hline Hooke-Jeeves & $(3)$ & 7 & 1081 & 169 \\
\hline Hooke-Jeeves & $(2)$ & 2 & 65534 & 1347 \\
\hline Hooke-Jeeves & $(2)$ & 2 & 2 & 21 \\
\hline Powell & $(2)$ & 2 & 61 & 25 \\
\hline Powell & $(3)$ & 7 & 1081 & 26 \\
\hline Powell & $(3)$ & 7 & 65534 & 49 \\
\hline Powell & $(2)$ & 2 & & 567 \\
\hline Powell & $(2)$ & 2 & & 2 \\
\hline
\end{tabular}

\section{Discussion}

The application presented in this article is a comprehensive tool for identifying rheological equations. Users can easily upload a stress-strain data from the mechanical tests. Once an inverse analysis is done user's interface allows to navigate through results representations as a table or a chart intuitively. Users who are familiar with the optimization methods can compare results of two available algorithms. Default setting - contains commonly used Hooke-Jeeves algorithm and the Hollomon's Eq. (2) that should return acceptable approximation results for various mechanical tests. The Hollomon's Eq. (2) is very universal. However, results of approximation using a more specialized rheological Eq. (3) were better, as both tools managed to find smaller goal function value than using the Hollomon's Eq. (2). Solution of the task 1 using the Hollomon's Eq. (2) obtained with the presented web application was close to the Excel Solver's solution. Identified parameters shown in Table I and minimum values of the goal function presented in Table II obtained with both compared tools were very similar. The stress-strain curves approximated as the task 1's solutions shown in Fig. 1 are very similar to each other. However, Table III shows that the developed tool approximated stress-strain curve with larger percent of points that are approximated with the RMSE smaller than 5. In a more advanced task 2 there is a slightly bigger difference between the compared software. Minimum value of the goal function Eq. (1) shown in Table $\mathrm{V}$ obtained with the Excel Solver is smaller than obtained using the developed web application. However, the stress-strain curves presented in Fig. 4 approximated with both tools have many common points with the experimental stress-strain curve. A comparison shown in Table VI shows that the Excel Solver approximated $14 \%$ more stress-strain curve points with good enough precision.

The execution time of each test was measured 10 times in the Table VII by averaging the result. Data with 37 points of approximated strain-stress curve refers to the time taken to complete the task 1 , while data containing 61 points of stress-strain relates to task 2 . As it is presented the time of typical task in which the input has several dozen points of the stress-strain curve does not exceed $100 \mathrm{~ms}$. Input with more points has been generated for the efficiency test. Time of approximation of stress-strain curve having over 65000 points uses the Hooke and Jeeves algorithm, and is equal less than one and a half seconds, which is an acceptable result. The calculation time for the tested functions is shorter with the Powell algorithm, but this advantage is not enough in comparison to the much less accurate result obtained by the Powell algorithm. The conclusion of Powell algorithm application was obtained on the basis of own tests in which stress-strain curves with parameters determined by the Powell method had smaller percentage of common points with the experimental curve than the curves with the parameters determined by the Hooke-Jeeves method.

Development of the presented web application is still in progress. Despite of results obtained with the developed tool which are not as good as those computed with the commercial Excel Solver, presented application has two big advantages over it. First advantage is a nature of the web application, it is possible to use it with any device having a web browser anytime. Second advantage is ease of use, there is no need of typing any formulas, configuring a solver and determining how to present data in a chart. The stress-strain curves data is passed to PrimeFaces chart component which automatically fits all the chart settings like axes to be displayed properly. When using the Excel user must manually select data for a chart which may lead to mistakes. After creating the chart with Excel user is often obligated to set axes scales add proper descriptions etc. Usage of the presented web application instead of the Excel for identifying allows user to save time giving properly scaled chart that may be exported as an image for reasons like for example: printing, sending as an e-mail, adding to a presentation, using in any other software for further processing or visualizing results. Additional advantage of the developed software is possibility of selecting different optimization methods, which might be expanded in future.

A calculation time of a single inverse problem on a common computer is short and acceptable even for large data inputs and multi-parameter rheological equations. However, efficiency of the presented application hosted on a public accessible server with many users remains unknown. Current architecture of the presented application does not use micro services, which means that even if it was hosted in a large distributed network, it would work the same as if it were on a single server. Converting some of the application's processes to be executed as the micro services would improve its efficiency when used in a distributed network. 


\section{Conclusions}

Results and discussion lead to the following conclusions:

- The proposed web application results are close to the commercial Excel Solver solution.

- The developed application has ergonomic user interface build of PrimeFaces components.

- The application's object oriented architecture is maintainable and allows to extending its features easily.

- Hooke-Jeeves and Powell algorithms used in the developed application are state-of-art solutions, using modern, hybrid search methods would improve results.

- The application's efficiency is acceptable in local networks, but it's current software design is not prepared for processing a data from many users simultaneously in a distributed network.

- Before publishing in the Internet, developed application security shall be improved and then checked with penetration tests.

\section{Acknowledgements:}

Financial assistance of the Ministry of Science and Higher Education in Poland, project no. 11.11.110.593.

\section{REFERENCES}

1. Rusin T., Kopernik M. "Characterization of biocompatible materials using stereomicroscope 3D digital image correlation". Advanced Engineering Materials. 18 (2016): s. 1651-1660.

2. Feipeng Z., Pengxiang B., Jingbin Z., Dong L., Xiaoyuan H. "Measurement of true stress-strain curves and evolution of plastic zone of low carbon steel under uniaxial tension using digital image correlation". Optics and Lasers in Engineering. 65 (2015): s. 81-88.

3. Zhao K., Wang L., Chan Y., Yan J. "Identification of post-necking stress-strain curve for sheet metals by inverse method". Mechanics of Materials. 92 (2016): s. 107-118.

4. Gavrus A., Massoni E., Chenot J.L. "An inverse analysis using a finite element model for identification of rheological parameters". Journal of Materials Processing Technology. 60 (1996): s. 447-454.

5. Szeliga D., Pietrzyk M. "Testing of the inverse software for identification of rheological models of materials subjected to plastic deformation". Archives of Civil and Mechanical Engineering. 7 (2007): s. $35-52$.

6. Kowalski B., Sellars M., Pietrzyk M. "Development of a computer code for the interpretation of results of hot plane strain compression tests". ISIJ International. 40 (2000): s.1230-1236.

7. Kopernik M., Milenin A., Major R., Lackner J.M. "Identification of material model of TiN using numerical simulation of nanoindentation test". Materials Science and Technology. 27 (2011): s. 604-616.

8. Rios L.M., Sahinidis N.V. "Derivative-free optimization: a review of algorithms and comparison of software implementations". Journal of Global Optimization. 56 (2013): s. 1247-1293.

9. Kirgat G.S., Surde A.N. "Review of Hooke and Jeeves direct search solution method analysis applicable to mechanical design engineering". IJIERT. 1 (2014): s. 1-14.

10. Calışkan M., Varaksin O. "PrimeFaces Cookbook". Birmingham: Packt Publishing, 2013.

11. Brittain J., Darwin I.F. "Tomcat: The Definitive Guide". Sebastopol: O'Reilly Media, Inc., 2007.

12. Kumar A.A., Prasad A.R. "Comparison of unconstrained search methods for correlation of binary vapor liquid equilibrium (VLE) by five variants of Wilson model". Journal of Chemical Engineering and Materials Science. 3 (2012): s. 58-64.

13. Lewis R.M., Torczon V., Trosset M.W. "Direct search methods: then and now". Journal of Computational and Applied Mathematics. 124 (2000): s. 191-207.

14. Moiseev S. "Comparison of Multivariate Optimization Methods". Maple Soft: 2006. https://www.maplesoft.com/applications/view. aspx?SID=1718\&view=html (dostep: 09.05.2018 r.).

15. Hollomon J.H. "Tensile deformation". Transactions of the Metallurgical Society of AIME. 162 (1945): s. 268-290.

16. Kopernik M. Spychalski M., Kurzydłowski K.J., Pietrzyk M. "Numerical identification of material model for C-Mn steel using micro-indentation test". Materials Science and Technology. 24 (2008): s. $369-375$.
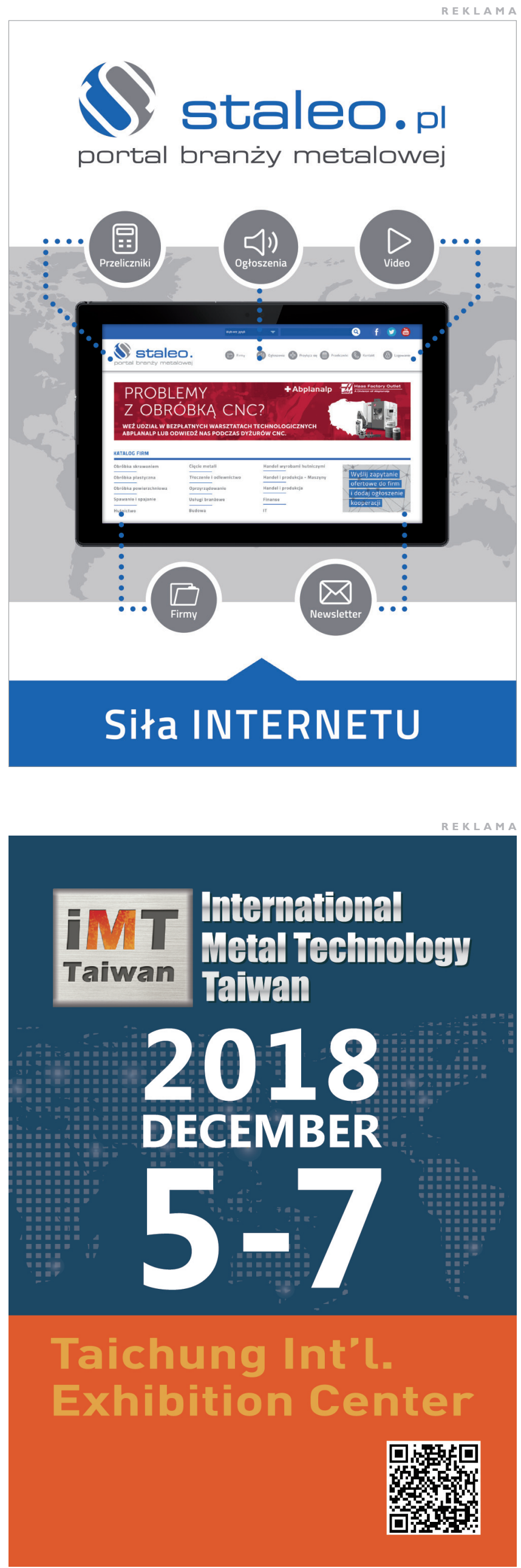